

\title{
Minha Vida Em Cor-De-Rosa: Cenas e Encenações da Transexualidade Feminina na Infância!
}

\author{
Mi Vida En Color Rosa: ¡Escenas e Interpretaciones de la Transexualidad \\ Femenina en la Infancia!
}

\section{My Life In Pink: Scenes and Stagings of Female Transsexuality in Childhood!}

\begin{abstract}
Resumo
No presente artigo discuto a transexualidade feminina na infância. Utilizo como objeto de análise o filme Minha Vida em Cor-de-Rosa (BERLINER, 1997) e o documentário Meu Eu Secreto (GOLDBERG, 2007), procurando fazer uma relação com o debate atual sobre Ideologia de Gênero. Meu interesse, então, se concentra nas ideias centrais das duas produções, ou seja: a transição do gênero masculino para o feminino, a patologização e despatologização das identidades trans, a relação entre o sexo anatômico e identidade de gênero, violência simbólica, cis heteronormatividade e adultocentrismo. Para fazer esse debate recorro as reflexões de John Thompson (2009) sobre comunicação de massa e violência simbólica, os estudos de gênero e diversidade sexual, bem como os estudos pós-estruturalistas, especialmente a obra de Michel Foucault.
\end{abstract}

Palavras-Chave: Identidade de gênero; Transexualidade; Infância; Violência simbólica; Sociedade.

\section{Resumen}

En el presente articulo discuto la transexualidad femenina en la infancia. Utilizo como objetivo de análisis la película Mi Vida en Color Rosa (BERLINER, 1997) y el documental Mi Yo Secreto (GOLDBERG, 2007), intentando hacer una relación con el debate actual sobre Ideología de Género. Mi interés, en tanto, se concentra en las ideas centrales de las dos producciones, o sea: la transición del genero masculino para el femenino, la patologización y despatologización de las identidades trans, la relación entre sexo anatómico e identidad de género, violencia simbólica, cis heteronormatividad y adultocentrismo. Para generar ese debate recorro las reflexiones de John Thompson (2009) sobre comunicación de masas y violencia simbólica, los estudios de género y diversidad sexual, como también los estudios post estructuralistas, especialmente la obra de Michel Foucault.

Palabras-Clave: Identidad de género; Transexualidad; Infancia; Violencia simbólica; Sociedad.

\begin{abstract}
In this article I discuss female transsexualism in childhood. I use the film My Life in Pink (BERLINER, 1997) and the documentary My Secret Self (GOLDBERG, 2007) as objects of analysis, trying to relate them to the current debate on the Ideology of Gender. My interest, then, focuses on the central ideas of the two productions, namely: the transition from male to female gender, the pathologization and depatologization of trans identities, the relations between anatomical sex and gender identity, symbolic violence, cis-heteronormativity and adultcentrism. To make this debate, I turn to John Thompson's (2009) reflections on mass communication and symbolic violence, gender studies and sexual diversity, as well as to poststructuralist studies, especially Michel Foucault's work.
\end{abstract}

Keywords: Gender identity; Transsexuality; Childhood; Symbolic violence; Society. 
As cores rosa e azul representam de forma bastante específica, em várias culturas, o universo feminino e masculino respectivamente, a fim de informar, ainda antes mesmo de nascer, a maneira correta como cada criança deve ser tratada a fim de terem fortalecidos os elementos constitutivos de sua feminilidade ou masculinidade associadas diretamente ao seu sexo biológico.

Rogério Diniz Junqueira ${ }^{1}$ (2009, p. 20) usa os estudos de Elisabeth Badinter (1995) e Gláucia Eliane Silva de Almeida (1995) para afirmar que "a masculinidade é considerada algo a ser duramente conquistada pelos indivíduos do sexo masculino, ao passo que a feminilidade é percebida como um componente natural da mulher". Já no trabalho de César Sabino, também estudado por Junqueira (2009), a masculinidade está associada a demonstrações de força, destemor e virilidade, construídas em contraposição a determinadas características femininas.

Assim, os códigos de conduta ensinados às crianças estabelecem que "o único lugar habitável para o feminino é em corpos de mulheres, e para o masculino, em corpos de homens" (BENTO, 2008, p. 25), "premiando os normatizados com respeito e oportunidades, e castigando as diferenças com desprezos e obstáculos" (PERES, 2009, p. 237), expondo de forma bastante objetiva que nas sociedades patriarcais não há outra possibilidade se não o ajustamento.

É a família heteronormativa, ou seja, aquela definida pela prática do "sexo bem- educado ou normatizado, isto é, as práticas heterossexuais, monogâmicas, consolidadas pelo matrimônio e reprodutivas" (CÉSAR, 2009, p. 43) o modelo de organização social que deve ser preservado e, para tanto, as pessoas precisam ser ensinadas, desde muito cedo, a agir de modo que consigam reproduzi-lo no futuro.

Essa é a visão das igrejas cristãs, que ao longo do tempo tem se esforçado para impor padrões únicos de comportamento que tomam a cis ${ }^{2}$ heterossexualidade como modelo único de existência.

A medida que a sociedade muda e propõe rupturas, o discurso religioso se atualiza, bem como seus mecanismos de controle.

Em 1997 o cardeal Joseph Aloisius Ratzinger, atual Papa Emérito Bento XVI, reforçava em seus escritos que a biologia determinaria o gênero e "que a liberação da mulher serve de centro nuclear para qualquer atividade de

1 Por defender uma educação não sexista além de utilizar o gênero feminino e masculino para me referir às pessoas em geral, na primeira vez que há a citação de um(a) autor(a), transcrevo seu nome completo para a identificação do sexo (gênero) e, consequentemente, para proporcionar maior visibilidade às pesquisadoras e estudiosas. 


\section{Feminina na Infância!}

liberação tanto política como antropológica com o objetivo de liberar o ser humano de sua biologia" (RATZINGER, 1997, p. 142). Ratzinger (1997) dava, então, o pontapé inicial para o surgimento de um debate que hoje é conhecido por Ideologia de Gênero.

Na definição de Jorge Scala (2010), discutida por Richard Mikolski e Maximiliano Campana (2017), a Ideologia de Gênero é um instrumento político-discursivo de alienação com dimensões globais que busca estabelecer um modelo totalitário com a finalidade de 'impor uma nova antropologia' a provocar a alteração das pautas morais e desembocar na destruição da sociedade.

Ao dirigir um ataque às lutas feministas e apontar o caminho para o desenvolvimento do conceito de Ideologia de Gênero, o cardeal Ratzinger (1997) procurava atingir, de acordo com Mikolski e Campana (2017) a Conferência Mundial de Beijing sobre a Mulher, organizada pelas Nações Unidas, em 1995, pela ousadia de propor substituir o termo 'mulher' (que havia sido o principal sujeito nas primeiras três conferências) pelo conceito de gênero, possibilitando que essa categoria fosse ampliada não se restringindo apenas a questões biológicas.

Assim, "nessa conferência se reconheceu que a desigualdade da mulher é um problema estrutural e só pode ser abordada de uma perspectiva integral de gênero" (MIKOLSKI; CAMPANA, 2017, p. 727), chamando a atenção para a necessidade de se olhar para os múltiplos sujeitos que expressam identidades femininas, como travestis e mulheres transexuais.

Tais declarações:

colocaram a categoria "gênero" no centro dos debates que giravam em torno do papel da mulher, provocando uma importante reação por parte de diversos setores religiosos conservadores e, em especial, da própria Igreja Católica. Assim, por causa dessa conferência, o papa João Paulo II, em sua "Carta às mulheres", se referiu à necessidade de defender a identidade feminina desde uma perspectiva essencialista e, alguns anos depois, na "Carta aos bispos", de 31 de maio de 2004, manifestou-se contra o discurso feminista, reiterando que a maternidade era um elemento-chave da identidade feminina (ponto 13). (MIKOLSKI; MAXIMILIANO, 2017, p. 727).

\footnotetext{
2 Cis é a abreviação de cisgênero. A noção de cisgeneridade é proposta pela transexual Julia Serano, em 2007, na obra Whipping girl: a transsexual woman on sexism and the scapegoating of femininity "a partir do exercício de analisar a origem da terminologia - trans-: o outro, o desajuste. Ligações químicas cruzadas espontaneamente, de forma inesperada. O oposto disso, o termo -cis-, também existe no campo da química orgânica: seria a ligação química esperada, a mais comum de se ocorrer entre os elementos. A ligação química "normal". Porém, as moléculas da química orgânica são imprevisíveis. Assim como as subjetividades são imprevisíveis. Portanto, a cisgeneridade indica a existência de uma norma que produz efeitos de ideal regulatório, ou seja, efeitos de expectativas e universalização da experiência humana. Em termos gerais, o que diferentes ativistas e os movimentos transfeministas têm proposto é que a norma cisgênera é uma das matrizes normativas das estruturas sociais, políticas e patriarcais, cujos ideais regulatórios produzem efeitos de vida e de atribuição identitária extremamente rígidos. A atribuição identitária, de forma compulsória no momento de registro de cada pessoa, define e naturaliza a designação de uma pessoa a um dos polos do sistema de sexo/gênero ao nascer, a partir de uma leitura restrita, baseada na aparência dos órgãos genitais. Além disso, a norma cisgênera afirma que essa designação é imutável, fixa, cristalizada ao longo da vida da pessoa." (CIDADE, 2016, p. 13-14).
} 


\section{Feminina na Infância!}

Ao destacar a maternidade como um elemento essencial da identidade feminina, o Papa João Paulo II assumia uma posição em relação a travestilidade e a transexualidade, concordando com as situações de exclusão e violação de direitos que recaiam sobre elas.

Ao fugir dos padrões preestabelecidos, travestis $^{3}$ e as transexuais ${ }^{4}$ são expostas a situações de discriminação e exclusão, podendo desenvolver estratégias de resistência que garantam seu direito de ser ou então buscando meios para uma adaptação que garanta ao menos sua sobrevivência, quase sempre caracterizados por discursos e atos de submissão e passividade (PERES, 2009, p.238).

No caso da criança transexual existe ainda o agravante de que pode ser vista como portadora de uma patologia que precisa e deve ser tratada, passando por experiências que evidenciam o quanto está em desacordo com os padrões preestabelecido e como é necessário que altere sua forma de pensar e agir para que possa se adequar ao sexo anatômico e assim levar uma vida 'normal'.

As cobranças impostas às crianças transexuais partem de vários segmentos de nossa sociedade - da família, da igreja, dos vizinhos, da escola, etc. restando pouco ou nenhum espaço para que possa se construir como sujeito, ainda mais quando suas reivindicações em adotar uma identidade de gênero diferente do sexo biológico são ignoradas, tratadas apenas como meras fantasias infantis, já que de modo geral, a infância está subalternizada em relação ao mundo dos adultos (SARMENTO; GOUVEA, 2008).

Essas questões são observáveis no Filme Minha Vida em Cor-de-rosa ${ }^{5}$ (La Vie em Rose), uma produção cooperativa entre Bélgica, França e Reino Unido de 1997, dirigida pelo belga Alain Berliner, que conta a história de Ludovic Fabre, uma menina transexual ${ }^{6}$ de sete anos de idade. Embora seja uma obra de ficção apresenta fortes semelhanças com a infância de muitas mulheres transexuais. Porém, acredito na possibilidade de outras formas de relacionamentos de crianças transexuais com suas famílias, com a escola e com a sociedade de um modo geral, por isso vou estabelecer um diálogo com o documentário Meu Eu Secreto (My Secret Self), produzido e apresentado pela Rede ABC de televisão dos Estados Unidos da América em 2007, que também discute transexualidade na infầncia. As histórias reais de duas meninas transexuais, Jess Jennings e Riley Grant, narradas no documentário serão utilizadas para dialogar com as situações vivenciadas pela personagem fictícia Ludovic Fabre no filme Minha Vida em Cor-de-Rosa.

3 Travesti é a pessoa "que vivencia o papel de gênero feminino, mas não se reconhece como homem ou como mulher, mas como membro de um terceiro gênero ou de um não-gênero" (JESUS, 2012, p.17).

4 Mulher transexual é toda pessoa que reivindica o reconhecimento social e legal como mulher (JESUS, 2012, p. 15).

5 A escolha desse filme se deu por ter sido lançado no mesmo ano em que o cardeal Joseph Aloisius Ratzinger, hoje Papa Emérito Bento XVI inicia um debate que hoje é conhecido como Ideologia de Gênero.

6 Nesse artigo reconheço a identidade feminina de Ludovic Fabre por entender que está perfeitamente consolidada no seu discurso, embora seja submetida a um tratamento no gênero masculino pela sociedade onde está inserida. 
Ambas as produções, embora tenham finalidades distintas, são consideradas como meios de comunicação de massa justamente por estarem disponíveis "a uma pluralidade de receptores" (THOMPSON, 2009, p. 287) e estão inseridas "dentro de uma Teoria do Cinema Queer, termo surgido no final dos anos de 1970/80, posterior aos genders studies, justificando a alta permeabilidade e artificialidade entre as identidades de gênero" (MACHADO, 2011, p. 11).

Queer sem um equivalente exato na língua portuguesa "pode ser traduzido por estranho, talvez ridículo, excêntrico, raro, extraordinário" (LOURO, 2004, p. 38). Para Judith Butler (2002), apontada como uma das precursoras da Teoria Queer, o termo tem operado uma prática linguística com o propósito de degradar os sujeitos aos quais se refere. "Queer adquire todo o seu poder precisamente através da invocação reiterada que o relaciona com acusações, patologias e insultos" (BUTLER, 2002, p. 58). Por isso, a proposta foi dar um novo significado ao termo, de positivá-lo, passando a entender queer como uma prática de vida que se coloca contra as normas socialmente aceitas.

Queer então pode ser interpretado como um processo, um movimento e aproxima-se das reflexões de Michel Foucault (1979) quando desenvolve o conceito de dispositivo. Para ele todo dispositivo "é sempre um dispositivo de poder" (CARNEIRO, 2005. p. 38), um lugar onde determinados sujeitos ganham visibilidade quando são interpretados como o contraponto da ordem.

Assim o conceito de dispositivo procura demarcar:

um conjunto decididamente heterogêneo que engloba discursos, instituições, organizações arquitetônicas, decisões regulamentares, leis, medidas administrativas, enunciados científicos, proposições filosóficas, morais, filantrópicas. Em suma, o dito e o não dito são os elementos do dispositivo. "O dispositivo é a rede que se pode estabelecer entre estes elementos. Em segundo lugar, gostaria de demarcar a natureza da relação que pode existir entre estes elementos heterogêneos. Sendo assim, tal discurso pode aparecer como programa de uma instituição ou, ao contrário, como elemento que permite justificar e mascarar uma prática que permanece muda; pode ainda funcionar como reinterpretação desta prática, dando-lhe acesso a um novo campo de racionalidade. Em suma, entre estes elementos, discursivos ou não, existe um tipo de jogo, ou seja, mudanças de posição, modificações de funções, que também podem ser muito diferentes. Em terceiro lugar, entendo dispositivo como um tipo de formação que, em um determinado momento histórico, teve como função principal responder a uma urgência. O dispositivo tem, portanto, uma função estratégica dominante" (FOUCAULT, 1979, p. 244).

No entanto, o mesmo Foucault (1982) que consegue perceber uma infinidade de mecanismos de controle, como o discurso da Ideologia de Gênero, por exemplo, operando de forma coordenada e simultânea, também identifica mecanismos para sua contraposição e afirma que onde há poder, há resistência. 
O cinema e a televisão são meios midiáticos expressivos, às vezes eficientes para narrar histórias que apresentam maior ou menor relação de similaridade com a vida real, reproduzindo modelos de feminilidade e masculinidade e arranjos familiares compatíveis, na maioria das vezes, com os padrões heteronormativos. A produção fílmica também pode produzir discursos que questionem criticamente os padrões que instituem a normatização dos gêneros (FERNANDES; SIQUEIRA, 2011).

Como meio de comunicação de massa o cinema e a televisão se caracterizam pela produção e difusão de formas simbólicas, ou seja, "uma ampla variedade de fenômenos significativos como ações, gestos, rituais, manifestações verbais, textos, obras de arte, objetos" (THOMPSOM, 2009, p. 183) que expressam, invariavelmente, relações assimétricas de poder.

As formas simbólicas não são permanentes e nem tão pouco fixas e podem ter seu significado modificado com o tempo e também serem recebidas e interpretadas de formas diferentes do seu contexto inicial. Há, no entanto uma intencionalidade que orienta o modo como são concebidas e uma expectativa de como devem ser recebidas (THOMPSOM, 2009).

É o caso do vestido rosa desejado por Ludovic, um signo que representa o universo feminino infantil onde pretende inserir-se. Sua opinião a respeito do que é ser menina é compartilhada por Jess Jenings e explica: é ter os cabelos compridos, furar as orelhas e usar sempre vestido, artefatos puramente culturais onde a genitália, se masculina ou feminina, tem pouca importância.

Jess Jennings tem seis anos e é a caçula de uma família 'comum' dos Estados Unidos da América. Vive com a mãe Reneé, com o pai Scotch e mais dois irmãos, gêmeos, e uma irmã.

Sua mãe conta que Jess, apesar de sua anatomia masculina, reivindicou aos 15 meses de vida o direito de ser tratada como menina e, logo que começou a falar, manifestou sua vontade em usar vestidos.

A insistência em ter sua identidade feminina reconhecida fez com que seus pais consultassem a Dra. Marilyn Volker especialista em sexo e transtorno de identidade de gênero que atestou sua transexualidade quando tinha apenas três anos. A partir do "diagnóstico" os pais explicaram a situação para os irmãos e a irmã que concordaram, sem resistência, em tratá-la como menina. Aos cinco anos, com o apoio dos pais, passou a viver integralmente como menina.

A maneira como Ludovic e Jess interpretam o que é ser menina se enquadra na opinião da maioria das pessoas, porém existem outras maneiras de se construir uma identidade feminina na infância sem vestidos ou bonecas e ainda assim operar dentro das normas cis heterossexuais padronizadas.

É o caso de Riley Grant que aos 10 anos prefere passar a maior parte do tempo com calças compridas e brincar com sua cobra de estimação. Talvez também porque seja mais velha que Jess e Ludovic e as bonecas e os vestidos já tenham cumprido suas funções, principalmente na fase de 'transição' do gênero masculino para o feminino.

Riley Grant também mora nos Estados Unidos, com a mãe Stephanie, com o pai Neil e com a irmã gêmea Ally. Assim como Jess começou a manifestar sua identidade de gênero feminino com poucos meses, reivindicando o direito 
Minha Vida Em Cor-De-Rosa: Cenas e Encenações da Transexualidade

\section{Feminina na Infância!}

de usar os brinquedos da irmã. O pediatra sugeriu aos pais que a colocasse em contato com brinquedos e atividades consideradas masculinas e corrigir suas atitudes inadequadas. Riley resistiu e conseguiu o que queria aos sete anos, sendo reconhecida finalmente como menina.

\section{O Filme}

Analisando a obra de John B. Thompsom (2009) é possível afirmar que as formas simbólicas nos acompanham a vida toda inclusive para reiterar formas explícitas de controle que visam a manutenção do poder, entendido como a capacidade de agir na busca de seus próprios objetivos.

Esse poder pode ser individual desde que os sujeitos se reconheçam nas formas simbólicas que os rodeiam. "Quando relações de poder estabelecidas são sistematicamente assimétricas, então a situação pode ser descrita como dominação" (THOMPSOM, 2009, p. 199).

As relações são assimétricas quando indivíduos ou grupos de indivíduos particulares possuem um poder estável de maneira a promover a exclusão de outros indivíduos ou grupos de indivíduos, resultando em dominantes e subordinados.

Ludovic Fabre é uma menina transexual fictícia com sete anos de idade que ganhou um corpo e uma voz através do trabalho magistral do ator Georges Du Fresne - e assim como Jess e Riley, se enquadra no grupo dos dominados, estando sujeita a regras e discursos que sistematicamente a exclui.

Ludo, como é carinhosamente chamada, é a caçula da família e vive numa pequena cidade francesa com a mãe Hanna, o pai Pierre, dois irmãos e uma irmã. Ainda luta para ter sua identidade de gênero reconhecida estando exposta a códigos de dominação que não considera a possibilidade de uma identidade feminina habitar um corpo anatomicamente masculino. As situações que enfrenta nos 88 minutos de filme mostram como pode ser doloroso esse processo, tanto para as pessoas trans, quanto para suas famílias.

A transexualidade de Ludovic Fabre, pouco ou nada compreendida pela família e pelos vizinhos, é motivo para situações de conflitos e discriminações. Uma discriminação inicialmente dirigida a ela e depois estendida a sua família.

Seus pais discordam de seu comportamento pouco comum de vestir roupas femininas, mas interpretam como uma brincadeira inocente dos seus primeiros anos de vida e que terá um final quando adquirir mais maturidade e estiver apta a entender e a incorporar o discurso presente na "ação pedagógica dos mais velhos" (SARMENTO; GOUVEA, 2008, p. 19). No entanto, o tempo faz com que essas atitudes se tornem mais frequentes passando a ser interpretadas como um problema, principalmente depois que aparece em público usando o vestido de princesa da irmã, maquiagem, brincos e salto alto numa festa em que sua família recebia os vizinhos pela primeira vez, já que acabavam de se mudar para aquele bairro.

Embora o filme se concentre na discussão da transexualidade de Ludovic, também discute os papéis de gênero a partir da biologia e quais espaços caberiam a homens e mulheres. Os homens são apresentados como os provedores, os responsáveis pelo sustento da casa e pela formação da personalidade dos filhos. As mulheres ficam restritas ao ambiente doméstico, 


\section{Feminina na Infância!}

são donas de casa e quando exercem ocupações fora do ambiente doméstico também se aproximam dos papéis maternos, como professora ou psicóloga de crianças. Nessa lógica, a identidade feminina se manifestaria de acordo como propõe João Paulo II e estaria ligada a maternidade, sendo impossível descolar o corpo biológico dos papéis sociais.

O mundo que circunda Ludovic é o ideal, com famílias cis heterossexuais brancas tradicionais e felizes que se comportam como vizinhos educados que se respeitam e se preocupam com a segurança uns dos outros. Não há pobreza, vícios, criminalidade, doenças, desordem. É um mundo cor-de-rosa sem gays, lésbicas, bissexuais, travestis, transexuais, negros(as), imigrantes, deficientes ou qualquer outra categoria que possa tirar a paz e o sossego. Todos(as) naquele bairro se encaixam perfeitamente ao padrão cis heteronormativo branco cristão. Menos Ludovic.

Dayana Brunetto Carlin dos Santos (2010) analisou a obra de Thomas Laqueur (2001) e afirma que a constatação da existência de dois sexos biológicos, masculino e feminino, no Ocidente, só ocorre ao longo do século XVIII. Antes, acreditava-se na existência apenas do sexo masculino, sendo a mulher um homem invertido com os órgãos sexuais masculinos na parte interna do corpo, sendo possível, em algumas situações, com o aumento da temperatura corporal, por exemplo, que um pênis se deslocasse para fora e viesse a ocupar o lugar da vagina. A mulher era um homem que não atingira a plenitude.

Mesmo conquistando um lugar na ciência como um ser individual completo, apartado do sexo masculino, a mulher continuou a ocupar um lugar subalterno na sociedade, desempenhando papéis, que na maioria das vezes, a mantinha enclausurada no ambiente doméstico.

Antes sua incompletude podia ser temporária, havendo a possibilidade de sua ascensão ao sexo masculino. Agora sua constituição biológica, como o oposto do homem, além de permanente confirmaria sua inferioridade.

Já as mulheres lésbicas eram obrigadas a reprimirem sua sexualidade, sendo punidas de forma severa caso tornasse pública sua orientação sexual. Já as mulheres transexuais não existiam. E no final do século XX na sociedade onde vive Ludovic elas também não deveriam existir. Assim, a certeza de Ludovic de que é uma menina vai sendo destruída pelo discurso cis heteronormativo dos adultos que insistem que o gênero é definido pelo sexo biológico. Suas convicções se transformam em dúvidas até chegar ao ponto de tentar ajustar-se a uma sociedade e a um corpo masculino que mal compreende.

Ludovic também não é respeitada porque é criança. Suas opiniões não são levadas a sério porque não é considerada um ser social com plenos direitos (SARMENTO; GOUVEA, 2008, p. 19).

As infâncias ao serem classificadas são enquadradas "a conceitos que as determinam como uma infância normal ou anormal. Disso advém uma contradição, ou seja, esta normalidade tem a norma como medida comum e que deverá ser seguida por todos" (DORNELES, 2010, p. 5).

Os padrões de normalidade tomam como modelo a 'infância universal"' (DORNELES, 2010) e que deve servir de modelo para todas as outras. À medida que se afasta desse modelo - branco, cis heterossexual, magro, sem problemas de saúde física e mental e de classe média -, a criança passa por um 


\section{Feminina na Infância!}

processo em que é vista como representante de uma 'infância perigosa' (NOGUERA-RAMÍREZ; MARÍN-DÍAZ, 2007) por colocar as infâncias universais em risco.

Entre as infâncias perigosas, DORNELES (2010) aponta aquela que está fora de casa, que acessa os materiais a serem consumidos via contravenção, que sobrevive e vive apesar dos riscos de seu cotidiano. Sobrevive nos bueiros e esgotos da vida urbana, mora embaixo de viadutos, pontes ou marquises de prédios.

As infâncias perigosas não têm cores, raças, orientações sexuais ou identidades de gênero. Têm apenas classe social, que é tomada como o marcador mais importante para estabelecer a aproximação ou o afastamento da "infância universal".

O potencial 'bélico' (NOGUERA-RAMÍREZ; MARÍN-DÍAZ, 2007) presente nos corpos de crianças transexuais as afastam da infância universal, talvez por isso suas existências não mereçam a devida atenção nos estudos sobre crianças.

De modo geral, as infâncias são tratadas como assexuadas ou como cis heterossexuais, contribuindo para a ausência de estudos que discutam as 'sexualidades disparatadas' (FOUCAULT, 1999) nessa fase da vida das pessoas.

A infância que o filme retrata é um pouco diferente da vivida por Jess Jennings e Riley Grant. Ambas conseguiram ser ouvidas por seus pais e terem suas identidades de gênero respeitadas depois de atestadas por especialistas, pois "não são apenas os adultos que intervêm junto das crianças, mas as crianças intervêm junto dos adultos" (SARMENTO; GOUVEA, 2008, p. 29). Jess aos três anos e Riley aos cinco. Durante dois anos tiveram o consentimento dos pais para se vestirem e agirem como meninas apenas dentro de casa, pois temiam atitudes hostis para com elas.

Jess Jennings apesar de deixar os pais confusos com sua insistência de que era uma menina, nunca foi punida por isso e podia explicitar seus desejos abertamente. Assim, aos dois anos perguntou a mãe quando a fada madrinha viria para trocar sua genitália. Reneé não ignorou a pergunta da filha e nem tampouco a considerou desconectada da realidade. A partir daí decidiu investigar o que aconteceria e a procurar informações mais seguras para lidar com a situação.

Ludovic além de expressar seu desejo de ser vista e tratada como menina, também insiste que um dia se casará com Jerome, vizinho e filho do chefe de seu pai, um personagem que sintetiza a visão hegemônica da criança bemeducada, por absorver todos os ensinamentos familiares e reproduzir de maneira exemplar o comportamento masculino ideal na infância, atendendo aos anseios daqueles que compartilham da ideia da existência da Ideologia de Gênero.

A ideia que Ludovic apresenta do que é ser menina, além de se vestir e portar-se como uma nos molde ocidentais, inclui uma relação afetiva ao lado de uma pessoa que apresenta características do gênero masculino, seguindo os padrões heteronormativos, revelando quem vai desempenhar os papéis femininos e masculinos nas relações sociais e sexuais futuras.

Há então, um processo de hiper-sexualização do seu discurso que resulta em

Megg Rayara Gomes de Oliveira 


\section{Feminina na Infância!}

ações mais coercitivas sobre si e Jerome e por isso se policiam quando discutem o futuro um ao lado do outro.

Em uma determinada cena do filme, na casa de Jerome, no quarto de sua irmãzinha morta, Ludovic experimenta sensações das mais agradáveis. É um quarto dos sonhos, um quarto de menina, com cores e brinquedos que evidenciam a visão que a sociedade adulta tem do feminino na infância.

Seus olhos percorrem cuidadosamente cada detalhe, se demorando aqui e ali, como se cada um deles, mesmo a meia luz, fosse a confirmação de sua feminilidade. Mas é o vestido cor-de-rosa, usado como a representação do universo feminino infantil em vários momentos do filme, que mais a encanta.

Sozinhos no quarto, livres de qualquer censura, encenam o casamento de sua heroína Pam com o namorado Ben. Ludovic é Pam e Jerome é Ben. Ludovic usa o vestido rosa e dirige a encenação. No entanto, o casamento é interrompido na hora do beijo do casal pelo desmaio da mãe de Jerome que, de mansinho, aproximou-se para espionar o que estava acontecendo. A mãe de Ludovic, que também estava em outro cômodo, se aproxima e a arrasta com violência de volta para casa.

Nesse momento Ludovic imagina que está sendo protegida por sua heroína Pam que amarra sua mãe e a mãe de Jerome com seu sopro mágico de purpurina dourada que toma a forma de um laço. Assim, ela, Jerome e Pam, podem voar livremente sem ninguém para impedir.

As formas simbólicas descritas por Thompson (2009) e os inúmeros Dispositivos identificados por Foucault (1979) como elementos de controle e manutenção do poder podem operar no sentido contrário, pois, "lá onde há poder há resistência" (FOUCAULT, 1982, p. 91). Assim Ludovic encontra no mundo fantástico de Pam uma maneira de resistir e alimentar o desejo de tornar-se definitivamente uma menina.

Foucault (1982) também afirma que a denúncia é uma forma de resistência. Nesse sentido, o diretor do filme Alain Berliner (1997) adota um discurso de resistência que fica mais explícito em algumas cenas, quando, por exemplo, recorre à introspecção de um quarto na penumbra para mostrar as condições de marginalidade impostas a população LGBT - Lésbicas, Gays, Bissexuais, Travestis e Transexuais, que se vê obrigada a buscar espaços específicos e reduzidos para vivenciar sua sexualidade e/ou identidade de gênero, ainda assim sujeita a vigilância e punições. O direito de ir e vir, assim como o de construir relações afetivas e arranjos familiares que fogem aos padrões dominantes, estão sujeitos ao julgamento e a aprovação de uma sociedade conservadora representada, nesse caso, pelas famílias, capazes inclusive, de destruir sonhos.

De acordo com Willian Siqueira Peres (2009) quando a travestilidade ou a transexualidade é expressa ainda na infância e depois na adolescência a história de vida dos sujeitos é marcada por discriminação, exclusão e violência, inclusive por parte da família. Embora concorde com Peres, compreendo a discriminação e a exclusão também como expressões de violência, já que dificultam ou impedem que suas vítimas possam viver plenamente em sociedade.

São estratégias que a família, a escola e a igreja utilizam, como aponta Foucault (1979) para exercerem seu controle sobre os corpos e determinarem o 
Minha Vida Em Cor-De-Rosa: Cenas e Encenações da Transexualidade

\section{Feminina na Infância!}

que é correto e moralmente aceito. Os(as) próprios(as) oprimidos(as), invariavelmente, são responsabilizados(as) pela situação de desvantagem em que se encontram, pois seus/suas agressores/agressoras alegam que as chances para um ajustamento social foi oferecida e desperdiçada por eles(as).

\section{Travestilidade e Transexualidade não é Pecado!}

O medo se configura num elemento importante na política de controle em qualquer instituição. No caso da igreja católica o pecado significa uma passagem para o inferno, punição máxima para os cristãos.

Esse é o recurso de convencimento utilizado pela família de Jerome para afastá-lo de Ludovic, e assim se vê obrigado a trocar de lugar na sala de aula para evitar tal castigo. Ao mudar de carteira dá a entender que Ludovic seria a própria representação do pecado e o simples ato de evitá-la garantiria sua salvação.

Esse e outros julgamentos a respeito de Ludovic fazem com que a vejam como portadora de uma patologia, precisando portanto de um tratamento. Sua ida a uma psicóloga confirma essa visão e é tratada como uma tentativa da família para "resolver o problema" e assim conviver em harmonia com a vizinhança que se sente no direito de intervir na educação dos filhos dos outros a partir de um pensamento consensual marcado pela intolerância.

A sociedade dos adultos composta por pessoas que agem dentro dos padrões ditos normais não é um lugar seguro para uma criança transexual. No caso de Ludovic, mesmo que não abdique verdadeiramente do desejo de ser uma menina, procura estabelecer uma aproximação com os códigos de comportamentos masculinos a fim de minimizar os conflitos em casa e na escola. Brincar de cowboy, jogar futebol ou beijar uma garota são ações que poderiam ajudá-la a se construir como menino e assim satisfazer a vontade das pessoas com quem convive, principalmente dos pais.

A busca por uma resposta para suas dúvidas se é menino ou menina a colocam em contato com uma resposta científica dada pela irmã mais velha que estudou o assunto nas aulas de ciências. XY determinaria o sexo biológico dos meninos e XX das meninas.

$\mathrm{Na}$ visão inocente de Ludovic seria Deus quem distribuiria essas letrinhas e o ' $\mathrm{X}$ ' que a definiria como menina teria caído no lixo por um capricho do destino. Essa explicação fantasiosa colocaria Ludovic em paz com o criador, porque originalmente teria sido a vontade dele que nascesse XX e não XY.

Riley Grant também atribui a responsabilidade de ter uma genitália masculina a Deus. Aos seis anos, enquanto fazia uma oração, revelou a sua mãe que estava muito brava com Deus: “- Ele me fez menino e eu não sou menino, sou menina mãe! Toda noite peço para Deus me dar um corpo de menina e quando acordo ainda sou menino. Deus não vai corrigir o erro, não vai fazer o certo" (Meu Eu Secreto - GOLDBERG, 2007, n. p.).

As explicações de Ludovic por mais fantasiosas que possam parecer, revelam sua disposição para se construir como mulher e encontram na fala de Riley, uma semelhança com a triste realidade enfrentada por muitas meninas transexuais.

Além da violência psicológica que sofre constantemente, Ludovic vivencia 


\section{Feminina na Infância!}

a experiência de ser agredida fisicamente no banheiro da escola, por um grupo de garotos, na presença dos irmãos mais velhos e de Jerome, que se isentam da responsabilidade de defendê-la. Tal situação faz com que ela se sinta extremamente deslocada, sem um espaço que possa ocupar, fazendo com que tente suicídio.

A agressão que as pessoas LGBT estão sujeitas, em muitos casos, é uma continuidade do discurso familiar que, em certa medida, acaba autorizando e até estimulando atitudes como essas, interpretadas por muitos, como corretivas.

A escola também representa um espaço hostil à população LGBT, sobretudo para as travestis e transexuais. Em suas pesquisas Peres (2009, p. 245) constata que "a partir da exclusão familiar e da vizinhança, as relações estabelecidas entre travestis, transexuais e transgêneros e a escola também se mostram bastante prejudicadas", pois acaba reproduzindo os modelos discriminatórios observados em outros espaços, promovendo invariavelmente sua expulsão.

No caso de Ludovic foi a própria escola que tomou a iniciativa de expulsála para assegurar a normalidade do ambiente, já que uma criança LGBT é "vista como uma ameaça à ordem estabelecida e capaz de ferir a imagem da moral e dos bons costumes" (PERES, 2009, p. 247).

Ludovic é vítima de um processo descrito por Peres (2009) como estigmatização que promove a depreciação e desvalorização dos sujeitos, a partir da introjeção de valores e de modos de ver que justificam sua desqualificação e exclusão, fazendo com que se torne cada vez mais vulneráveis diante da vida, perdendo a força de questionamento e da crítica. A estigmatização se propaga como ondas, partindo da família para a comunidade e demais espaços.

Assim, resistir a esse processo que cobra um ajustamento e estabelece relações assimétricas de poder, se torna cada vez mais difícil, uma vez que a transexualidade ao ser censurada, é entendida como inexistente, ilícita e, portanto não deve ser falada até ser anulada no real (FOUCAULT, 1982).

\section{Finalmente Menina!}

A construção de uma identidade de gênero, feminina ou masculina, tem nos cabelos um elemento simbólico dos mais importantes. Deixá-los crescer, em muitas sociedades, significa identificar-se como mulher e cortá-los é aproximar-se de uma identidade masculina, necessitando no caso das crianças, do consentimento da família. Assim, "a intervenção no cabelo e no corpo é mais que uma questão de vaidade ou de tratamento estético. É identitária" (GOMES, 2008, p. 21).

O cabelo como ícone identitário também pode ser interpretado como um veículo de expressão e resistência. Deixá-los crescer pode representar para uma menina transexual um meio de lutar contra a cis heteronormatividade, assim como mantê-los crespos pode ser uma maneira de uma pessoa negra lutar contra o padrão ideal branco (GOMES, 2008).

Os problemas que atingem a família Fabre têm em Ludovic o seu polo irradiador. Quando a casa da família é pichada com uma frase homofóbica mais uma vez Ludovic é responsabilizada e num ato de desespero e de 


\section{Feminina na Infância!}

finalmente colocar um ponto final em suas atitudes inadequadas, a mãe cortalhes os cabelos diante dos olhares do pai e dos irmãos. É um momento de sofrimento coletivo tratado como se fosse um ritual religioso, um exorcismo que vai expulsar em definitivo as forças malignas que atormentam aquela família.

Cortar os cabelos de Ludovic e expô-la aos olhares da vizinhança é o reconhecimento da vitória da intolerância e do desamparo a que uma pessoa transexual está sujeita dentro da própria casa. A certeza de que não pode contar com o apoio dos pais faz com que Ludovic decida viver com sua avó, onde se sente menos agredida e poderá, se construir com alguma liberdade mesmo que seja em um mundo inventado ao lado de sua heroína Pam onde pode se casar com Jerome com a aprovação de todo mundo.

Os laços familiares desfeitos, ou nesse caso apenas afrouxados, podem ser construídos novamente. Essa possibilidade de um desfecho menos trágico para as pessoas transexuais é que vai se desenhando no final do filme, que acena para a possibilidade de as famílias reverem seus pontos de vistas e assim acolher e não excluir seus filhos e filhas transexuais.

A mudança de emprego de Pierre, o pai, faz com que Ludovic volte para casa. No filme a mudança de emprego, de cidade, de vizinhos, etc. é uma metáfora que alerta para a necessidade de mudanças também no modo de trato com aqueles que não apresentam identidades exatamente padronizadas.

Tal mudança acontece depois de uma série de tentativas frustradas de construir uma identidade masculina em Ludovic chegando aos extremos de uma surra, justamente em um momento em que ela parecia disposta a desistir de se construir como menina para evitar mais aborrecimentos para a família, mesmo que isso significasse anulá-lo como pessoa.

A compreensão de que Ludovic precisa de apoio se manifesta na passividade de suas atitudes que revelam ter chegado ao limite da resistência.

Ao contrário de Hanna Fabre, personagem fictícia e que representa o modo de pensar de muitas mães de crianças transexuais, Renée Jennings decidiu apoiar a filha e ficar na frente de batalha e receber toda a artilharia pesada antes que Jess seja machucada e pergunta: “- Que criança merece sofrer?” (Meu Eu Secreto - GOLDBERG, 2007, n. p.).

Para responder a essa questão, recorro a Beatriz Preciado (2013), hoje Paul Preciado, que explica que uma criança não tem autonomia sobre si mesma e "é sempre um corpo ao qual não se reconhece o direito de governar" (PRECIADO, 2013, p. 97).

Uma criança transexual coloca em risco um projeto de futuro, um empreendimento fadado ao fracasso. O futuro que importa anunciado por uma criança só pode ser aceitável se corresponder à norma cis heterossexual branca.

Preciado (2013) se preocupa com as outras crianças. Aquelas que borram as fronteiras dos gêneros, a cis heterossexualidade; e lançam dúvidas se vale a pena um investimento sobre elas.

Preciado (2013, p. 97), então, pergunta:

Quem defende o direito das crianças diferentes? Os direitos do menino que adora se vestir de rosa? Da menina que sonha em se casar com a sua melhor amiga? Os direitos da criança bicha, sapatão, 
transexual ou transgênero? Quem defende o direito da criança a mudar de gênero, se for da vontade dela? Os direitos das crianças à livre autodeterminação de gênero e de sexualidade? Quem defende os direitos da criança a crescer num mundo sem violência sexual ou de gênero?

Essas crianças não deveriam existir e, por isso mesmo, precisam ser eliminadas rapidamente. Controlar seu gestual, seu vocabulário, suas vestimentas, seus atos, enfim, controlar o próprio sujeito é fundamental para assegurar um futuro normalizado e normatizado.

A família de Ludovic Fabre, desafiou essas regras e, depois de muitos conflitos e sofrimentos, decidiu acolhê-la e apoiá-la incondicionalmente, afirmando o amor e não o ódio como o sentimento que deve estar presente nas relações familiares.

\section{Algumas Considerações}

Minha Vida em Cor-de-Rosa não termina como um conto de fadas que diz 'e assim, viveram felizes para sempre', pois as situações de conflitos estarão sempre na ordem do dia na vida de uma pessoa transexual.

Ainda assim a mensagem que fica é de esperança. Esperança no amor incondicional entre pais e filhos(as). Esperança de que a transexualidade não seja interpretada como aberração ou patologia e que move as famílias Jennings e Grant, e assim trabalham para que suas filhas transexuais cresçam numa sociedade menos preconceituosa.

Essa esperança não é tratada como mera abstração ou fantasia, mas como o resultado concreto de reivindicações que partem dos próprios sujeitos e são endereçadas a segmentos importantes de nossa sociedade como a família e a escola. Assim, o enfrentamento do preconceito e a inserção da população LGBT teriam início dentro de casa para depois ser estendido a outros espaços como a vizinhança, a escola, até atingir toda a sociedade, numa operação contínua, marcada por dores, angústias, agressões, tropeços, mas principalmente, como propõe Foucault (1982), por resistência!

Assim as formas simbólicas presentes no filme Minha Vida em Cor-de-Rosa (BERLINER, 1997) e no documentário Meu Eu Secreto (GOLDBERG, 2007), apesar dos 10 anos que os separam, apontam para uma possibilidade diferente daquela apresentada inicialmente por Thompson (2009) que as vê como uma das muitas formas de operação do poder, justamente por adquirirem contornos de denúncia e não uma mera reprodução dos discursos hegemônicos.

Em ambas as produções o debate a respeito de uma visão adultocêntrica de sociedade é central e apontam para a necessidade de que as crianças, mesmo as menores com um ou dois anos, sejam tratadas como sujeitos de direitos e que suas reivindicações, por mais distantes que possam estar da realidade cotidiana vivenciada por seus familiares, precisam sim ser levadas em consideração, ainda que seja necessário desafiar cânones e padrões de comportamento considerados únicos.

Minha Vida em Cor-de-Rosa é lançado exatamente no mesmo ano em que as bases para a formulação do conceito de Ideologia de Gênero são 
Minha Vida Em Cor-De-Rosa: Cenas e Encenações da Transexualidade

\section{Feminina na Infância!}

construídas. Coincidência ou não, o filme é uma contra resposta ao debate proposto pelo Cardeal Ratzinger (1997) que procura negar de forma muito objetiva o direito a existências que questionam a relação entre as identidades sociais e o sexo anatômico.

Ainda que nenhuma das produções se proponham a dialogar diretamente com setores mais conservadores das sociedades ocidentais, acabam por acenar para o fato de que é possível a inserção de múltiplos sujeitos sociais sem que a família cis hetero nuclear branca seja destruída.

\section{Referências}

ALMEIDA, G. E. S. de. Da invisibilidade à vulnerabilidade: percursos do "corpo lésbico" na cena brasileira face à possibilidade de infecção por DST e Aids. 1995. (Doutorado em Saúde Coletiva). - Universidade Estadual do Rio de Janeiro, Rio de Janeiro - RJ.

BADINTER, E. XY: sobre a identidade masculina. Rio de Janeiro: Nova Fronteira, 1995.

BENTO, B. A. de M. O que é transexualidade? São Paulo: Brasiliense, 2008 (Primeiros Passos n. 328).

BUTLER, J. Críticamente subversiva. In: JIMÉNEZ, R. M. M. Sexualidades transgresoras. Una antología de estudios queer. Barcelona: Icária editorial, 2002. p. 55-79.

CÉSAR, M. R. de A. Gênero, sexualidade e educação: notas para uma Epistemologia, Educar em Revista, n. 35, p. 37-51, set.- dez. 2009.

CIDADE, M. L. R. Nomes (im)próprios: registro civil, norma cisgênera e racionalidades do sistema judiciário. 2016. Dissertação (Mestrado em Psicologia) - Universidade Federal do Rio de Janeiro, Rio de Janeiro.

DORNELES, L. V. Sobre o devir-criança ou discursos sobre as infâncias. In: COLÓQUIO INTERNACIONAL DE FILOSOFIA DA EDUCAÇÃO, 5., 2010. Anais... Rio de Janeiro, 2010. p. 1-19.

FERNANDES, W. R.; SIQUEIRA, V. H. F. Cinema e relações de gênero: ouvindo mulheres idosas. In: REUNIÃO ANUAL DA ASSOCIAÇÃO NACIONAL DE PESQUISA E PÓSGRADUAÇÃO EM EDUCAÇÃO, 29, Caxambú. Anais... Caxambu: ANPED, 2006. p. 1-16.

FOUCAULT, M. Microfísica do Poder. Rio de Janeiro: Edições Graal, 1979. 1982.

História da sexualidade 1: a vontade de saber. Rio de Janeiro: Graal,

Em defesa da sociedade: curso no College de France. São Paulo: 
Minha Vida Em Cor-De-Rosa: Cenas e Encenações da Transexualidade

Feminina na Infância!

Martins Fontes, 1999.

GOMES, N. L. Sem perder a Raiz: Corpo e cabelo como símbolos da identidade negra. Belo Horizonte: Autêntica, 2008.

JESUS, J. G. de. Orientações sobre a população transgênero: conceitos e termos. Brasília: Autor, 2012.

JUNQUEIRA, R. D. Homofobia nas escolas: um problema de todos. In: JUNQUEIRA, R. D. (Org.). Diversidade sexual na educação: problematizações sobre a homofobia nas escolas. Brasília: Ministério da Educação, Secretaria de Educação Continuada, Alfabetização e Diversidade, UNESCO, 2009. p. 13-51.

LAQUEUR, Thomas. Inventando o sexo: corpo e gênero dos gregos à Freud. Rio de Janeiro: Relume Dumará, 2001.

LOURO, G. L. Um Corpo Estranho: Ensaios Sobre Sexualidade e Teoria Queer. Belo Horizonte: Autêntica, 2004.

MACHADO, A. O diabo rouba a cena: A representação marginal em Madame Satã. 2011. (Graduação em Jornalismo). - Universidade Federal de Santa Maria, Santa maria - RS.

MEU Eu Secreto. Produção: Alan B. Goldberg. New York: Rede ABC de televisão, 2007. Título original: My secret self.

MIKOLSKI, R.; CAMPANA, M. "Ideologia de gênero": notas para a genealogia de um pânico moral contemporâneo. Revista Sociedade e Estado, v. 32, n. $3,725-747$, set./dez. 2017.

MINHA vida em cor-de-rosa. Direção: Alain Berliner. Produção: Carole Scotta. França/Bélgica/Reino Unido: Haut \& Court Production, 1997. Título Original: Ma vie en rose.

NOGUERA-RAMÍREZ, C.; MARÍN-DÍAZ, D. La infancia como problema o el problema de la infancia. Revista Colombiana de Educación. Bogota, n. 53, p.107-

126. 2 sem. 2007.

PERES, W. S. Cenas de exclusões anunciadas: travestis, transexuais, transgêneros e a escola brasileira. In: JUNQUEIRA, R. D. (Org.). Diversidade sexual na educação: problematizações sobre a homofobia nas escolas. Brasília: Ministério da Educação, Secretaria de Educação Continuada, Alfabetização e Diversidade, UNESCO, 2009. p. 235-264.

PRECIADO, B. Quem defende a criança queer? Tradução: Fernanda Ferreira Marcondes Nogueira. Jangada, n. 1, p. 96-99, jan-jun. 2013. 
Minha Vida Em Cor-De-Rosa: Cenas e Encenações da Transexualidade

Feminina na Infância!

RATZINGER, J. A. La sal de la tierra. Madrid: Libros Palabra, 1997.

SANTOS, D. B. C. dos. Cartografias da transexualidade: a experiência escolar e outras tramas. 2010. Dissertação (Mestrado em Educação) Universidade Federal do Paraná, Curitiba-PR.

SARMENTO, M.; GOUVEA, M. C. S. de. Estudos da Infância: educação e práticas sociais. Petropólis-RJ: Vozes, 2008.

SCALA, J. La ideología del género: O el género como herramienta de poder. Rosario: Ediciones Logos, 2010.

THOMPSON, J. B. Ideologia e cultura moderna: teoria social crítica na era dos meios de comunicação de massa. Petrópolis: Vozes, 2009. 